\title{
Paroxysmal Nocturnal Hemoglobinuria Type III Lack of an Erythrocyte Membrane Protein Restricting the Lysis by C5b-9
}

\author{
Gertrud M. Hänsch, Sabine Schönermark, and Dieter Roelcke \\ Institut für Immunologie der Universität Heidelberg, 6900 Heidelberg, Federal Republic of Germany
}

\begin{abstract}
The complement-mediated lysis is inefficient when complement and target cells are homologous with regard to the species. In erythrocytes from patients suffering from paroxysmal nocturnal hemoglobinuria (PNH), the species restriction is lost: PNHerythrocytes (PNH-E) are susceptible to lysis by human complement. In human erythrocytes (huE) the species restriction is ascribed to an integral membrane protein, designated C8-binding protein (C8bp). In the present study, we tested membranes of PNH-E type III for the presence of C8bp. A protein with C8binding capacity could not be detected. C8bp, which was isolated from the membrane of huE, inhibited the lysis of PNH-E by C5b-9 as well as the $\mathbf{C 9}$ polymerization. Thus, addition of $\mathbf{C} 8 \mathrm{bp}$ restored the species restriction in PNH-E. In conclusion, we propose that lack of $\mathbf{C 8 b p}$ might represent the defect in PNHE type III membranes, which is responsible for their enhanced lytic susceptibility towards lysis by the late complement components.
\end{abstract}

\section{Introduction}

The complement-mediated lysis is inefficient when complement and target cells are from the same species $(1,2)$. The so-called "species restriction" is most probably due to membrane proteins interfering with the complement-membrane interactions at different steps of the complement cascade $(3,4)$. In paroxysmal nocturnal hemoglobinuria (PNH), ${ }^{1}$ a disease characterized by an abnormal sensitivity of the patient's erythrocytes (PNH-E) to complement-mediated lysis, the species restriction is apparently lost (5-8). In many studies, enhanced uptake of C3 is noted $(9,10)$. The enhanced C3 uptake is due to the lack of a regulatory membrane protein, the so-called decay-accelerating factor (DAF) $(11,12)$. DAF inhibits the formation of the C3-convertases of either the classical or the alternative pathway of complement activation. Lack of DAF results in enhanced formation

Data was partly presented at the 6th International Congress of Immunology, Toronto, Canada, 6-11 July 1986.

Please address all correspondence to Dr. G. M. Hänsch, Institut für Immunologie, Im Neuenheimer Feld 305, 6900 Heidelberg, FRG.

Received for publication 4 November 1986.

1. Abbreviations used in this paper: C8bp, C8-binding protein; DAF, decay-accelerating factor: huE, human erythrocytes; $\mathrm{PNH}$, paroxysmal noctural hemoglobinuria; PNH-E, erythrocytes of patients suffering from PNH; VBS, veronal-buffered saline.

J. Clin. Invest.

(c) The American Society for Clinical Investigation, Inc.

0021-9738/87/07/0007/06 \$2.00

Volume 80 , July $1987,7-12$ of C3-convertases, leading to an increased activation of the lytic complement complex (11-14). PNH-E of some patients (type III), however, are also more susceptible to lysis by the late complement components C5b-9. Therefore, in addition to the impaired regulation at the $\mathrm{C} 3 \mathrm{step}$, the interaction of the late complement components with the membrane is affected in PNH-E type III (15-19). Indeed, $\mathrm{Hu}$ and Nicholson-Weller (20) recently reported increases in binding of C9 to PNH-E type III in comparison with normal human erythrocytes (huE). Furthermore, a higher degree of $\mathrm{C} 9$ polymerization is seen, whereas insertion efficiency of C9 is similar in PNH-E and normal huE. The enhanced susceptibility of PNH-E to C5b-9 appears to be species specific, i.e., lysis is only enhanced when PNH-E-C5b67 intermediates are lysed by human but not guinea pig C8 and C9 (21, 22). Thus, the lack of a factor restricting the lysis of huE seemed probable. Recently we identified a protein in huE membranes with the functional properties of a factor restricting the lysis by the late complement components $\mathrm{C} 5 \mathrm{~b}-9$. This protein binds isolated human C8 and inhibits the lysis of erythrocytes-C5b67 intermediates by human $\mathrm{C} 8$ and $\mathrm{C} 9$, but not by $\mathrm{C} 8$ and $\mathrm{C} 9$ of another species $(4)$. It is distinct from $\operatorname{DAF}(3,4)$ and was tentatively designated C8-binding protein (C8bp). In the present study, we tested if erythrocyte membranes of patients suffering from PNH contained C8bp. The PNH-E that could be classified as type III, based on their susceptibility towards complement C5b-9, did not contain a C8bp, which suggests that in PNH-E of type III lack of C8bp might be responsible for the enhanced lytic susceptibility of these cells.

\section{Methods}

Buffers. For the hemolytic assays, $\mathrm{DGVB}^{++}(50 \mathrm{ml}$ veronal-buffered saline [VBS] mixed with $50 \mathrm{~g}$ dextrose and $0.1 \mathrm{~g}$ gelatin in $1,000 \mathrm{ml}$ distilled water that contained $\mathrm{MgSO}_{4}$ and $\mathrm{CaCl}_{2}$ in final concentrations of 5.5 $\times 10^{-4}$ and $1.5 \times 10^{-4} \mathrm{M}$, respectively) was used (23).

Erythrocytes. huE (blood group zero, ccddee) were obtained from our blood bank. They were washed repeatedly in $\mathrm{DGVB}^{++}$and adjusted to $1 \times 10^{8} / \mathrm{ml}$. PNH-E were obtained from five patients: A.K., Klinikum Mannheim der Universität Heidelberg, Federal Republic of Germany; A.A. and R.Sch., Medizinische Klinik der Universität Heidelberg; and E.M. and F.A., Medizinische Klinik, Freiburg, Federal Republic of Germany. The normal huE used as control were taken from healthy volunteers at the same time as the PNH-E. The patients' erythrocytes and the normal huE were washed and adjusted to $1 \times 10^{8} / \mathrm{ml}$. PNH-E (five patients) were susceptible to lysis by acid-activated serum or C5b-9; thus, they were classified as type III (Table I). Erythrocyte membranes were prepared by lysing erythrocytes with buffer containing 0.1 M EDTA, 20 $\mathrm{mM} N$-ethylmaleinimid, and $1 \mathrm{nM}$ phenyl-methyl-sulfoxid adjusted to pH 7.4 by $1 \mathrm{M}$ Tris (24). Furthermore, lyophilized membrane preparations of exclusively type III PNH-E were obtained from Dr. Rosse's laboratory (Duke University Medical Center, Durham, NC). PNH-E were separated from normal erythrocytes by adsorbing the latter to an unsolubilized antibody to acetylcholinesterase as described (25).

Complement components. The human complement components $\mathrm{C} 5$, C6, and C7 were isolated as described by Hammer et al. (26). C8 and 
C9 were prepared according to the methods of Monahan et al. (27) and Rauterberg et al. (28), respectively. Functionally pure rabbit $\mathrm{C} 8$ and $\mathrm{C} 9$ were isolated by using similar techniques as Schönermark et al. (4) and Hänsch et al. (29), respectively. To generate an active C5b6, partially purified C5 $(400 \mu \mathrm{g})$ and $\mathrm{C} 6(200 \mu \mathrm{g})$ were mixed and activated by a C3convertase. The resulting $\mathrm{C} 5 \mathrm{~b} 6$ activity was further purified by anionexchange chromatography and gel filtration as described by Yamamoto and Gewurz (30). Hemolytic activity was calculated as hit per cell (Z) (23). As a further source of complement, a C8-deficient serum from a patient with a genetic $\mathbf{C} 8$ defect was used.

Acid activation of normal human serum or C8-deficient human serum. To avoid activation of the early components, the serum containing 0.01 $M$ EDTA was adjusted to $\mathrm{pH} 6.4$ at $4^{\circ} \mathrm{C}$ with $0.5 \mathrm{M} \mathrm{HCl}$, then neutralized with $1 \mathrm{M} \mathrm{NaOH}$ and used immediately (31).

Hemolytic assays. To generate C5b67 intermediates, $1 \mathrm{ml}$ of huE was incubated with $2 \mathrm{ml} \mathrm{C5b6}$ for $5 \mathrm{~min}$ at room temperature. Then 1 $\mathrm{ml} \mathrm{C7}$ was added. After incubation for $30 \mathrm{~min}$ at $30^{\circ} \mathrm{C}$, the erythrocytes were washed and resuspended in $1 \mathrm{ml} \mathrm{DGVB}{ }^{++} .0 .1 \mathrm{ml}$ of these intermediates were lysed by addition of $0.1 \mathrm{ml} \mathrm{C} 8$ and $0.1 \mathrm{ml} \mathrm{C} 9$ and by incubation for $40 \mathrm{~min}$ at $37^{\circ} \mathrm{C}$. $0.25-8 \mu \mathrm{g}$ of C5b6, $1 \mu \mathrm{g}$ of $\mathrm{C} 7$ and $1-4$ $\mu \mathrm{g}$ of $\mathrm{C} 8$ and $\mathrm{C} 9$ were used. When using whole or $\mathrm{C} 8$-deficient serum, $1 \times 10^{8} / \mathrm{ml}$ erythrocytes were incubated with $0.2 \mathrm{ml}$ acidified serum diluted 1:5 in VBS that contained 0.01 M EDTA. To prepare erythrocytes-C5b67 intermediates, $0.1 \mathrm{ml}$ erythrocytes were incubated with 0.2 $\mathrm{ml}$ acidified C8-deficient serum diluted 1:5 in VBS-EDTA for $30 \mathrm{~min}$ at $30^{\circ} \mathrm{C}$. Erythrocytes were then centrifuged and washed.

Isolation of C8 binding protein, C8bp. C8bp was isolated from huE membranes as described (4). huE were washed, treated with papain, and then lyzed. The membranes were collected and extracted with phenol water. The proteins of the water phase were further purified by preparative isoelectric focusing. By this procedure, a protein of $\sim 65,000 \mathrm{D}$ that yielded a single band in sodium dodecyl sulfate-polyacrylamide gel electrophoresis (SDS-PAGE) under reducing or nonreducing conditions was obtained.

Radiolabeling of C8bp. $1 \mathrm{mg}$ C8bp was labeled with ${ }^{125} \mathrm{~J}$ by using Bolton-Hunter reagent ( $250 \mu \mathrm{Ci}$, New England Nuclear, Braunschweig, Federal Republic of Germany) according to the manufacturer's instruction. Free ${ }^{125} \mathrm{~J}$ was removed by gelfiltration on Sephadex G-25 and by dialysis. About $10 \%$ of the radioactivity was associated with the C8bp.

Uptake of C8bp by PNH-E. $10^{9} / \mathrm{ml}$ PNH-E were incubated with 10 $\mu \mathrm{g}{ }^{125} \mathrm{~J}-\mathrm{C} 8 \mathrm{bp}$ for $30 \mathrm{~min}$ at $30^{\circ} \mathrm{C}$. The PNH-E were then washed repeatedly in DGVB ${ }^{++}$. Elution of C8bp was tested with $\mathrm{DGVB}^{++}$substituted for $0.15 \mathrm{M}$ up to $0.3 \mathrm{M} \mathrm{NaCl}$. For trypsinization, $1 \mathrm{mg} / \mathrm{ml}$ trypsin (Serva, Heidelberg, Federal Republic of Germany) was incubated with the PNH$\mathrm{E}$ for $30 \mathrm{~min}$ at $30^{\circ} \mathrm{C}$. After repeated washings, radioactivity that remained with the PNH-E as well as radioactive material released into the supernatant and the washing buffers were counted. To test association of ${ }^{125} \mathrm{~J}$ C8bp with the membranes, the PNH-E were lyzed as previously described. Membranes were collected by centrifugation (Sorvall, DuPont Instrument, Bad Nauheim, FRG; 20,000 rpm for $20 \mathrm{~min}$ ). Elution of ${ }^{125} \mathrm{~J}$ C8bp was assayed with buffer of various ionic strength or trypsin as described above. For solubilization of the membranes, Triton X-100 or Nonidet (final concentration $0.1 \% \mathrm{vol} / \mathrm{vol}$ ) were used.

Detection of C8bp. C8bp was detected as described (4). Erythrocyte membranes (equivalent to $200 \mu \mathrm{g}$ protein) were separated by SDS-PAGE in a Laemmli system (4-17\% gradient gel) (32). After electrotransfer of proteins to nitrocellulose, which was performed with minor modification (33), the nitrocellulose strips were incubated with 5-10 $\mu$ g purified $\mathrm{C8}$ for $2 \mathrm{~h}$ at room temperature. By using anti-C8 (IgG fraction purchased from Miles Ames Div., Miles Laboratories Inc., Elkart, IN) and a peroxidase-labeled anti-IgG (Sigma Chemical Co., St. Louis, MO), binding of $\mathrm{C} 8$ could be demonstrated. Nitrocellulose strips that were incubated with buffer instead of $\mathrm{C} 8$ and anti-C8, and anti-IgG, were used as control.

Preparation of an antibody directed against C8bp. Rabbits were injected subcutaneously with a mixture of $0.5 \mathrm{mg}$ purified C8bp and an equal volume of complete Freund's adjuvants. After 2 and 4 wk, the rabbits were boostered with C8bp emulgated with incomplete Freund's adjuvants. IgG was prepared from blood by ion-exchange chromatography.

Determination of $C 9$ polymerization. Complement-lysed erythrocyte membranes were separated by SDS-PAGE under reducing conditions as described by Podack and Tschopp (34). After blotting, C 9 monomers and polymers could be demonstrated.

\section{Results}

Test for C8-binding protein in the membrane of PNH-E. Erythrocytes of five patients (Table I), as well as a membrane preparation of type III erythrocytes were tested. The membranes were separated by SDS-PAGE. After Coomassie Blue staining, membranes of PNH-E showed a similar pattern as huE. After electrotransfer of the membrane proteins to nitrocellulose, binding of purified human $\mathrm{C} 8$ was tested. Using anti-C8 and a peroxidase-linked anti-IgG, binding of $\mathrm{C} 8$ to a protein of $\sim 65,000 \mathrm{D}$ was seen in huE, but not in PNH-E. The result is shown for patient A.A. and purified type III membranes in Fig. 1. When the electroblots were incubated with an antibody directed against $\mathrm{C} 8 \mathrm{bp}$, only in huE a band of $\sim 65,000 \mathrm{D}$ was seen; a very faint band was visible in the PNH-E taken from patient A.A. The membrane preparation containing only type III PNH-E did not have a band reacting with the anti-C8bp antibody (Fig. 2). By scanning, the intensity of the bands was determined in PNH-E of the other patients. The data are summarized in Table I. In addition to the 65,000-D band, there was also a band of $\sim 32,000 \mathrm{D}$ stained by anti-C8bp, which was missing in the PNH-E (Fig. 2).

Effect of purified C8bp on the lysis of PNH-E. The PNH-E (five different patients) were susceptible to lysis by acidified serum as well as by $\mathrm{C} 5 \mathrm{~b} 6, \mathrm{C} 7$, and human $\mathrm{C} 8$ and $\mathrm{C} 9$. To test if isolated C8bp would restore the homologous restriction in PNH-E, reincorporation of $\mathrm{C} 8 \mathrm{bp}$ was assayed. The PNH-E (patient F.A.) were incubated with ${ }^{125} \mathrm{~J}-\mathrm{C} 8 \mathrm{bp}$ and bound $\sim 10 \%$ of the ${ }^{125} \mathrm{~J}$ C8bp that was offered. Most of ${ }^{125} \mathrm{~J}-\mathrm{C} 8 \mathrm{bp}(\sim 90 \%)$ remained associated with the erythrocytes or membranes of erythrocytes,

Table I. Complement-Mediated Lysis of PNH-E and Normal huE in Relation to the Amount of C8bp

\begin{tabular}{clll}
\hline & \multicolumn{2}{l}{ Percent lysis by } & \\
\cline { 2 - 3 } Patient & $\begin{array}{l}\text { Acid-activated } \\
\text { serum }\end{array}$ & C5b-9 & $\begin{array}{l}\text { Relative amount } \\
\text { of C8bp }\end{array}$ \\
\hline & $\%$ & $\%$ & $m$ \\
PNH-E & & & \\
A.K. & 34 & 14 & 44 \\
A.A. & 56 & 36 & 14 \\
R.Sch. & 24 & 4 & 64 \\
E.M. & 51 & 38 & 22 \\
F.A. & 42 & 32 & 18 \\
huE & & & \\
S.F. & 18 & 0 & 82 \\
M.B. & 0.9 & 0 & 95 \\
\hline
\end{tabular}

* Estimated as peak height by scanning of an immunoblot stained with anti-C8bp. 

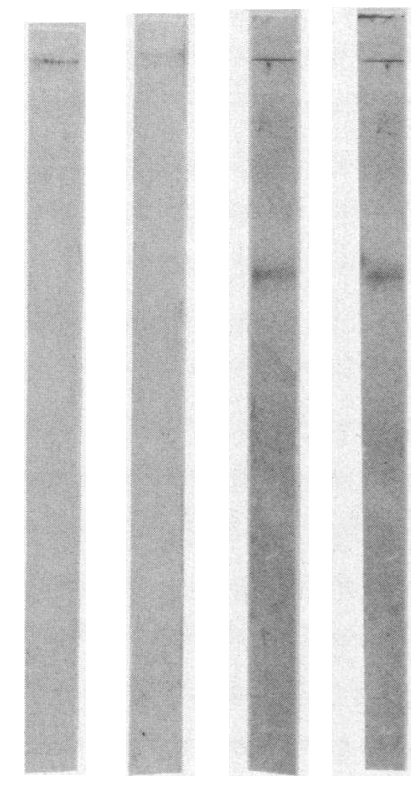

A B C

D

Figure 1. Test for C8bp in the membrane of PNH-E. Membranes of PNH-E (patient A.A.) (A), lyophilized-purified PNH-E membrane proteins $(B)$ or membranes of normal huE $(C)$ were separated by SDS-PAGE and then transferred to nitrocellulose. The blots were incubated with human C8, and binding of $\mathrm{C} 8$ was tested with an enzyme-linked antibody. $D$ shows the isolated C8bp.
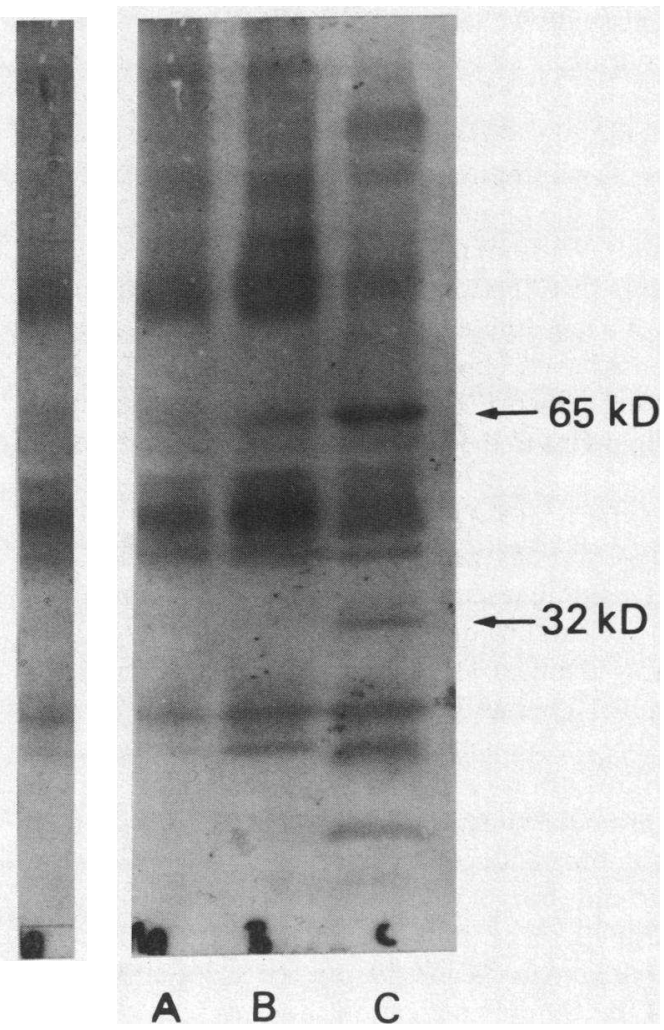

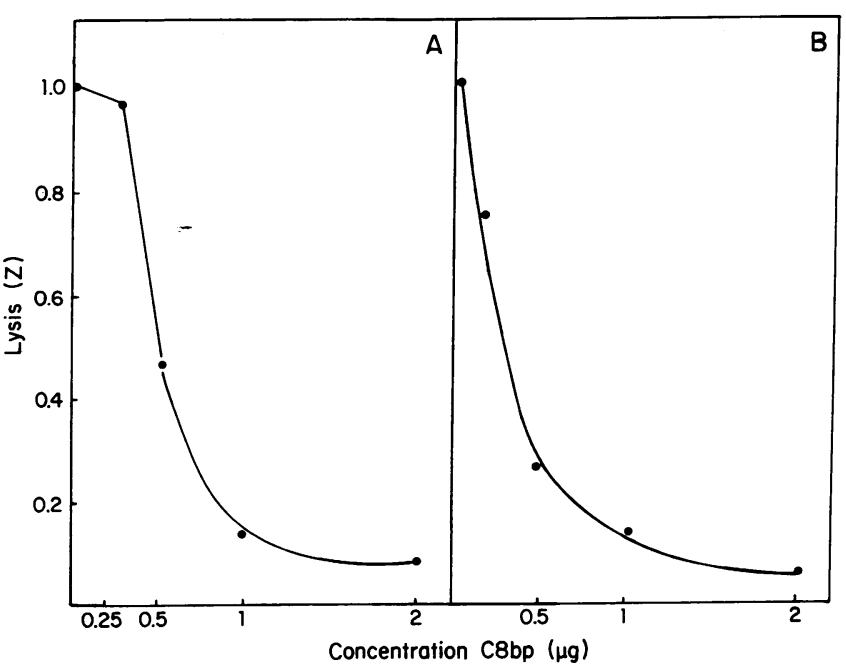

Figure 3. Inhibition of C5b-9-mediated lysis in PNH-E by C8bp. PNH-E were preincubated with purified $\mathrm{C} 8 \mathrm{bp}$ in different concentrations for $30 \mathrm{~min}$ at $30^{\circ} \mathrm{C}$. The washed cells were then lysed by human C5b-9. (A) Patient F.A. (B) Patient A.A.

respectively, even after washing in buffers containing $0.3 \mathrm{M}$ salt. From the membranes, ${ }^{125} \mathrm{~J}$ could only be extracted with detergents; trypsinization had no effect. In PNH-E that carried purified $\mathrm{C} 8 \mathrm{bp}$, the lysis by acidified human serum as well as by $\mathrm{C} 5 \mathrm{~b}-\mathrm{9}$ was inhibited (data shown for patients F.A. and A.A., Figs. 3 and 4). PNH-E bound up to $10^{5}$ molecules of C8bp per erythrocyte. $\sim 1,000$ molecules, however, were sufficient to yield a $50 \%$ inhibition of lysis.

Effect of C8bp on the $C 9$ polymerization. Recent data by $\mathrm{Hu}$ and Nicholson-Weller showed that in PNH-E, in contrast to huE, C9 polymerization was seen after treatment with whole human complement. Therefore, we tested if $\mathrm{C} 8 \mathrm{bp}$ would affect the $\mathrm{C} 9$ polymerization. To yield a high number of $\mathrm{C} 7$ sites, in these experiments the erythrocytes were loaded with acid-activated C8-deficient human serum. The washed erythrocytes were then incubated either with C8bp and excess of partially purified C8 plus C9 or with $\mathrm{C} 8$ and $\mathrm{C} 9$ alone. After incubation for 60 min at $37^{\circ} \mathrm{C}$, the nonlysed erythrocytes were removed, and the membranes were collected and separated by SDS-PAGE. Using

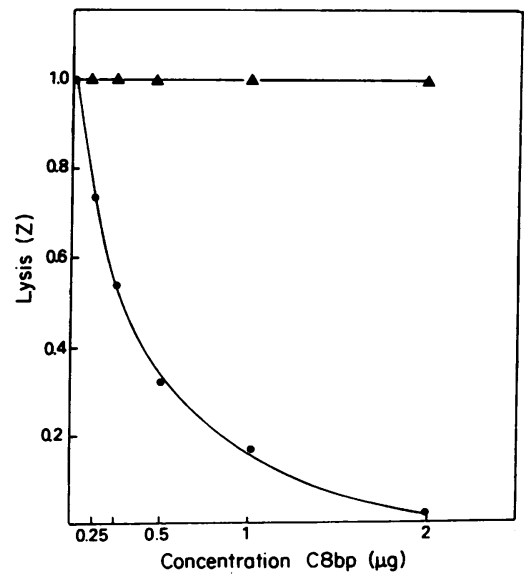

Figure 4. Inhibition of C5b-9-mediated lysis by C8bp. C5b67 intermediates were formed on PNH-E and incubated with C8bp in various concentrations. Then human $\mathrm{C} 8$ and $\mathrm{C} 9(\bullet)$ or rabbit $\mathrm{C} 8$ and $\mathrm{C} 9(\mathbf{A})$ was added in excess.
Figure 2. Test for C8bp with use of an antibody. Lyophilized membrane of purified PNH-E $(A)$, of a patient suffering from PNH-E type III $(B)$, or of a healthy individual $(C)$ were separated by SDS-gel and blotted to nitrocellulose. Then anti-C8bp was added and followed by a peroxidase-linked anti-IgG. On the far right, purified C8bp is shown. On the far left, a band of normal huE membranes that were incubated with the preimmune serum is shown. 


\section{PNH-E NHE}
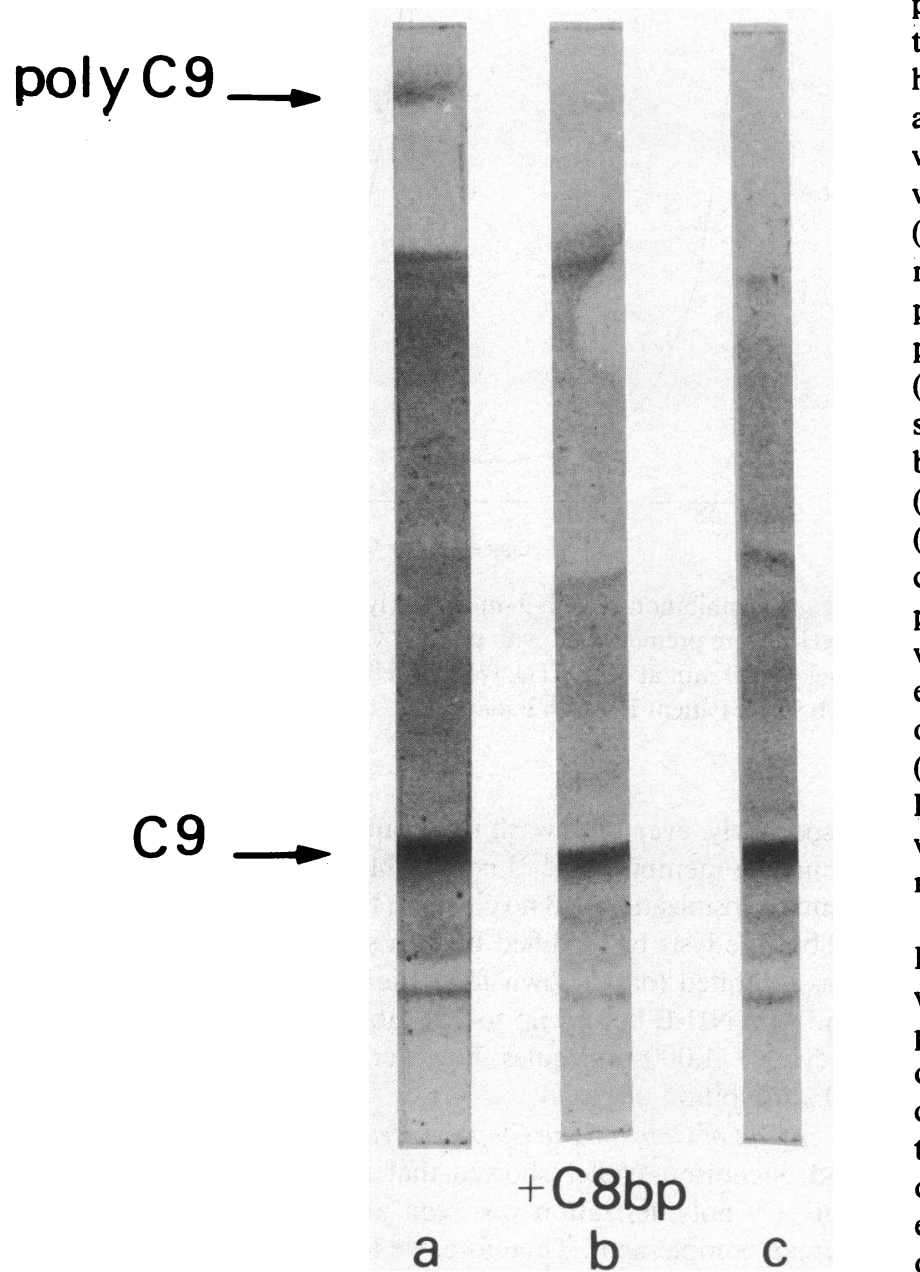

Figure 5. Inhibition of $\mathrm{C} 9$ polymerization by $\mathrm{C} 8 \mathrm{bp}$. $\mathrm{C} 1-7$ intermediates were formed on either PNH-E or normal huE. PNH-E-C1-7 intermediates were then incubated with excess human $\mathrm{C} 8$ and $\mathrm{C} 9$ in the absence $(a)$ or presence $(b)$ of $C 8 \mathrm{bp}$. Membranes were collected, separated by SDS-PAGE, and blotted; $\mathrm{C} 9$ was identified by anti-C 9 and an enzyme-linked anti-IgG. (c) shows the blot of normal huE lysed by antibody and excess of human complement. NHE, normal huE.

PNH-E, a band that could be identified by immunoblot as polyC9 was seen on top of the gel (Fig. 5). Using normal huE, the poly-C9 band was missing (Fig. 5). When, however, the PNHE-C1-7 intermediates were incubated with C8bp and excess of human $\mathrm{C} 8$ and $\mathrm{C} 9$, the formation of poly-C9 was inhibited (data shown for patient A.A., Fig. 5).

\section{Discussion}

In 1937, Ham described that PNH-E could be lyzed by acidactivated serum (1). Acidification of human serum (i.e., shift of serum $\mathrm{pH}$ to 6.4) causes, independent of the C3-convertases, the generation of a C56 complex, termed $C(56)^{a} . C(56)^{a}$ together with $\mathrm{C} 7, \mathrm{C} 8$, and $\mathrm{C} 9$ cause lysis of chicken erythrocytes or PNH$\mathrm{E}(22,31)$.
Enhanced lytic susceptibility of PNH-E by human complement was also seen; it was activated by antigen-antibody complexes or by the alternative pathway (6-9). While investigating the reason for the enhanced lytic susceptibility of PNH-E by human complement, it was noted that PNH-E bind much higher amounts of $\mathrm{C} 3$ than normal huE $(9,10)$. Enhanced $\mathrm{C} 3$ uptake was due to the lack of an intrinsic membrane protein, DAF, which regulates the formation and decay of the C3-convertases (12-14). Enhanced uptake of C3, however, cannot be the only reason for the abnormal sensitivity of PNH-E, because in some patients enhanced susceptibility towards lysis by the late complement components C5b-9 (16-21) or $C(56)^{2}-9(22)$ is also seen (i.e., in the total absence of $\mathrm{C} 3$ ). The reason for the enhanced susceptibility is still under investigation; meanwhile, enhanced binding of the components of the attack phase has been suggested (35). Other authors, however, reported that in absence of C3 (i.e., using isolated $\mathrm{C5b6}, \mathrm{C7}, \mathrm{C} 8$ and $\mathrm{C}$ ) the uptake and incorporation of the components into the membrane-attack complex is equal to that of normal erythrocytes (36). When, however, whole serum was used, enhanced C9 uptake was seen as well as enhanced $\mathrm{C} 9$ polymerization (20). The enhanced lysis was only observed when human and not guinea pig C8 and C9 were used $(21,22)$. Therefore, it was reasonable to postulate that in PNHE type III the factor restricting the lysis in the homologous system was missing. A membrane protein with properties of a speciesrestricting factor was described recently (4).

In the present study we tested, if this $\mathrm{C} 8 \mathrm{bp}$ was present in PNH-E. In the purified PNH-E membranes, C8bp was missing when tested by binding of isolated $\mathrm{C} 8$ or by antibody. In the patients the amount of $\mathrm{C} 8 \mathrm{bp}$ was greatly reduced. Being aware of the problems of quantitating from an immunoblot, a rough correlation between the amount of $\mathrm{C} 8 \mathrm{bp}$ and the lytic susceptibility was obvious. Whether the erythrocytes in PNH expressed only low amounts of $\mathrm{C} 8 \mathrm{bp}$, or there were two populations of erythrocytes, a normal one expressing C8bp and an afflicted one, which did not have $\mathrm{C} 8 \mathrm{bp}$, cannot be decided yet. The fact, however, that the purified PNH-E did not contain measurable amounts of $\mathrm{C} 8 \mathrm{bp}$ points to the possibility of different erythrocyte populations.

In addition to the $65,000-\mathrm{D}$ band, a further band of $\sim 32,000$ D stained by anti-C8bp was seen, which was missing in the PNHE. Whether this band represents another form of C8bp or a split product is not yet clear; however, it most likely indicates a form of $\mathrm{C} 8 \mathrm{bp}$, probably identical with inhibitory protein described by Zalman and Müller-Eberhard (36).

Isolated C8bp was reincorporated into membranes. After lysis of the erythrocytes it remained associated with the membranes. C8bp cannot be eluted by buffers in high-ionic strength, but it can by nonionic detergents or SDS. Addition of C8bp to PNH-E restored the homologous species restriction: purified C8bp inhibited the lysis of PNH-E or PNH-E-C5b-7 intermediates by $\mathrm{C} 5 \mathrm{~b}-9$ or human $\mathrm{C} 8$ and $\mathrm{C} 9$, respectively. Furthermore, C8bp inhibited the $\mathrm{C} 9$ polymerization that was seen after lysis by human complement in the membrane of PNH-E, but not in normal huE.

How C8bp in normal erythrocytes restricts the lysis is not yet known. From our recent data (4) and the comparison of lysis of huE, PNH-E, and PNH-E coated with C8bp we like to propose the following reaction mechanism: in a heterologous system or a model lipid membrane, C8 (bound to the C5b-7 
complex) binds $\mathrm{C} 9$ and is thought to catalyze $\mathrm{C} 9$ polymerization (33). Even though it is doubtful if $\mathrm{C} 9$ polymerization is a prerequisite for lysis, it still serves as a suitable indicator of the $\mathrm{C8}$ C9 interaction. Most probably the C8 $\alpha$-chain is involved in C9 polymerization (37), whereas binding to the C5b67 complex is mediated by the $\beta$-chain. The C8 $\alpha$ - $\gamma$-subunit also binds the $\mathrm{C} 8 \mathrm{bp}$ (38), which is in accordance with the fact that C8bp does not interfere with the binding of $\mathrm{C} 8$ to $\mathrm{C} 5 \mathrm{~b}-7$; instead, it interferes with one of the sequential reactions (i.e., inhibition of $C 9$ polymerization) and probably also with C5b-9 insertion. Since the $\mathrm{C} 8 \mathrm{bp}$ function was missing, uptake of $\mathrm{C} 5 \mathrm{~b}-8$ would not be affected; however, the C8-C9 interaction would be modulated: enhanced uptake of $\mathrm{C} 9$ might occur as well as $\mathrm{C} 9$ polymerization and probably also enhanced C5b-9 insertion. In this respect, PNH-E behaved exactly like cells with a $\mathrm{C} 8 \mathrm{bp}$ function missing: normal uptake of C5b-8 $(18,20)$ is seen, but enhanced uptake of $C 9$ and C9 polymerization was observed as well as enhanced lysis. Considering that a $\mathrm{C} 8 \mathrm{bp}$ function could not be demonstrated, we propose that a protein with C8-binding capacity was the species-restricting inhibitor in the lysis of huE, and that a lack of this inhibitor-as it is seen in patients suffering from PNH type III-results in enhanced susceptibility towards lysis by the late complement components.

\section{Acknowledgments}

We thank Dr. Schröder, Med. Klinik der Universität Heidelberg, Federal Republic of Germany and Dr. H.-H. Peter, Med. Klinik Freiburg, Federal Republic of Germany for supplying the PNH-E. Furthermore, we thank Dr. Dana Devine and Dr. W. Rosse (Duke University Medical Center) for providing membranes of isolated PNH-E and control erythrocytes.

\section{References}

1. Bordet, J. 1900. Les serum hemolytiques, les antitoxins et les theories des serums cytolytique. Ann. l'Inst. Pasteur (Paris). 14:257-271.

2. Hänsch, G. M., C. H. Hammer, P. Vanguri, and M. L. Shin. 1981. Homologous species restriction in lysis of erythrocytes by terminal complement proteins. Proc. Natl. Acad. Sci. USA. 78:5118-5121.

3. Shin, M. L., G. M. Hänsch, V. Hu, and A. Nicholson-Weller. 1986. Membrane factors responsible for homologous species restriction of complement-mediated lysis: DAF operates at the $\mathrm{C} 3 / \mathrm{C} 5$ convertase, while a second pronase sensitive factor(s) operates at $\mathrm{C} 8$ and $\mathrm{C} 9$ reaction. J. Immunol. 136:1776-1782.

4. Schönermark, S., E. W. Rauterberg, M. L. Shin, S. Löke, D. Roelcke, and G. M. Hänsch. 1986. Homologous species restriction in lysis of human erythrocytes: a membrane-derived protein with C8-binding capacity functions as a inhibitor. J. Immunol. 136:1772-1776.

5. Ham, T. H. 1936. Chronic hemolytic anemia with paroxysmal nocturnal hemoglobinuria: study of the mechanism of hemolysis in relation to acid-base equilibrium. $N$. Engl. J. Med. 217:915-921.

6. Rosse, W. F., G. L. Logue, J. P. Adams, and J. H. Crookston. 1974. Mechanism of immune lysis of the red cells in hereditary erythroplastic multinuclearity with a positive acidified serum test and paroxysmal nocturnal hemoglobinuria. J. Clin. Invest. 53:31-43.

7. Rosse, W. F., and J. V. Dacie. 1966. Immune lysis of normal and paroxysmal nocturnal hemoglobinuria cells. I. The sensitivity of PNH red cells to lysis by complement and specific antibody. J. Clin. Invest. 45:736-744.

8. Schreiber, A. D. 1983. Paroxysmal nocturnal hemoglobinuria revisited. N. Engl. J. Med. 309:723-725.

9. Logue, G. L., W. F. Rosse, and J. P. Adams. 1973. Mechanism of immune lysis of red cells in vitro. Paroxysmal nocturnal hemoglobinuria cells. J. Clin. Invest. 52:1129-1137.
10. Parker, C. J., P. J. Baker, and W. F. Rosse. 1982. Increased enzymatic activity of the alternative pathway convertase when bound to erythrocytes of paroxysmal nocturnal hemoglobinuria. J. Clin. Invest. 69:337-346.

11. Nicholson-Weller, A., J. Burge, D. T. Fearon, P. F. Weller, and K. F. Austen. 1982. Isolation of a human erythrocyte membrane glycoprotein with decay accelerating activity for $\mathrm{C} 3$-convertases of the complement system. J. Immunol. 129:184-189.

12. Nicholson-Weller, A., J. P. March, S. I. Rosenfeld, and K. F. Austen. 1983. Affected erythrocytes of patients with paroxysmal nocturnal hemoglobinuria are deficient in the complement regulatory protein decay accelerating factor. Proc. Natl. Acad. Sci. USA. 80:5066-5070.

13. Pangburn, M. K., R. D. Schreiber, J. S. Trombold, and H. J. Müller-Eberhard. 1983. Paroxysmal nocturnal hemoglobinuria: deficiency in factor H-like functions of the abnormal erythrocytes. J. Exp. Med. 157:1971-1980.

14. Medof, M. E., T. Kinoshita, and V. Nussenzweig. 1984. Inhibition of complement activation on the surface of cells after incorporation of decay-accelerating factor (DAF) into their membranes. J. Exp. Med. 160:1558-1578.

15. Rosse, W. F. 1973. Variations in red cells in paroxysmal nocturnal hemoglobinuria. Br. J. Haematol. 24:327-342.

16. Packman, C. H., S. I. Rosenfeld, D. E. Jenkins, P. A. Thiem, and J. P. Leddy. 1979. Complement lysis of human erythrocytes: differing susceptibility of two types of paroxysmal nocturnal hemoglobinuria. $J$. Clin. Invest. 64:428-433.

17. Packman, C. H., S. I. Rosenfeld, D. E. Jenkins, and J. P. Leddy. 1980. Complement lysis of human erythrocytes. II. A unique interaction of human C8 and C9 with paroxysmal nocturnal hemoglobinuria erythrocytes. J. Immunol. 124:2818-2823.

18. Rosenfeld, S. I., D. E. Jenkins, and J. P. Leddy. 1985. Enhanced lysis of paroxysmal nocturnal hemoglobinuria erythrocytes by C5b-9 does not involve increased binding of $\mathrm{C} 7$ or cell-bound C3. J. Immunol. 134:506-511.

19. Rosse, W. F. 1986. The control of complement activation by the blood cells in paroxysmal nocturnal hemoglobinuria. Blood. 67:286287.

20. Hu, V., and A. Nicholson-Weller. 1985. Enhanced complementmediated lysis of type III paroxysmal nocturnal hemoglobinuria erythrocytes involves increased $\mathrm{C} 9$ binding and polymerization. Proc. Natl. Acad. Sci. USA. 82:5520-5524.

21. Rosenfeld, S. I., C. H. Packman, D. E. Jenkins, J. V. Countryman, and J. P. Leddy. 1980. Complement lysis of human erythrocytes. III. Differing effectiveness of human and guinea pig $\mathrm{C} 9$ on normal and paroxysmal nocturnal hemoglobinuria cells. J. Immunol. 125:2063-2068.

22. Hänsch, G. M., C. H. Hammer, R. Jiji, U. Rother, and M. L. Shin. 1983. Lysis of paroxysmal nocturnal hemoglobinuria erythrocytes by acid-activated serum. Immunobiology. 164:118-121.

23. Mayer, M. M. 1961. Complement and complement fixation. In Experimental Immunochemistry. E. Kabat, and M. M. Mayer, editors. Charles C Thomas Publisher, Springfield, IL. 111-116.

24. Staros, J. V. 1982. N-hydroxysulfosuccinimide active esters: bis (N-hydroxysulfosuccinimide) esters of two dicarboxylic acids are hydrophilic membrane impermeant protein cross-linkers. Biochemistry. 21: 3950-3956.

25. Chow, F. L., S. E. Hall, W. F. Rosse, and M. J. Telen. 1986. Separation of the acetylcholinesterase-deficient red cells in paroxysmal nocturnal hemoglobinuria. Blood. 67:837-893.

26. Hammer, C. H., M. M. Frank, G. Wirtz, L. Renfer, H. Gresham, and B. Tack. 1981. Large scale isolation of functionally active components of the human complement system. J. Biol. Chem. 256:3995-4006.

27. Monahan, J. B., and J. M. Sodetz. 1980. Binding of the eighth components of human complement to the soluble cytolytic complex is mediated by its $\beta$-subunit. J. Biol. Chem. 255:10579-10582.

28. Rauterberg, E. W., Ch. Schieck, and G. M. Hänsch. 1979. Isolation of complement components by affinity chromatography. I. Purification 
of the human complement component $\mathrm{C} 9$ and production of a C9-defective human serum. Immunobiology. 155:365-377.

29. Hänsch, G. M., G. Rummel, and F. Gänzler. 1984. Purification and characterization of the ninth component of rabbit complement Complement. 1:116-122.

30. Yamamoto, K., and H. Gewurz. 1978. The complex of C5b and C6: isolation, characterization and identification of a modified form of C5b consisting in three polypeptide chains. J. Immunol. 120:2008-2015.

31. Rother, U., G. M. Hänsch, E. W. Rauterberg, H. Jungfer, and K. Rother. 1978. Deviated lysis: lysis of unsensitized cells by complement. V. Generation of the activity by low pH or low ionic strength. Z. Im munitaetsforsch. 155:118-129.

32. Laemmli, U. K. 1970. Cleavage of structural proteins during assembly of the head of bacteriophage T4. Nature (Lond.). 227:680-685.

33. Lucius, R., E. W. Rauterberg, and H. J. Diesfeld. 1983. Identification of immunogenetic proteins of Dipetalonema vitae (filarioidea) by the Western blotting techniques. Tropenmed. Parasitol. 34:75-81.
34. Podack, E. R., and J. Tschopp. 1982. Circular polymerization of the ninth components of complement. Ring closure of the tubular complex confers resistance to detergent dissociation and to proteolytic degradation. J. Biol. Chem. 257:15204-15212.

35. Parker, C. J., T. Wiedmer, P. J. Sims, and W. F. Rosse. 1986. Characterization of the complement sensitivity of paroxysmal nocturnal hemoglobinuria erythrocytes. J. Clin. Invest. 75:2074-2084.

36. Rosenfeld, S. I., D. E. Jenkins, and J. P. Leddy. 1986. Enhanced reactive lysis of paroxysmal nocturnal hemoglobinuria erythrocytes. Studies on C9 binding and incorporation into high molecular weight complexes. J. Exp. Med. 164:981-997.

37. Podack, E. R. 1985. Membrane attack by complement. Mol. Immunol. 21:589-603.

38. Hänsch, G. M., S. Schönermark, and D. Roelcke. 1986. The role of $\mathrm{C} 8$ binding protein in homologous species restriction of $\mathrm{C}$-mediated lysis: the C8bp interacts with $\alpha-\gamma$ subunit of C8, and inhibits C9 polymerization. Fed. Proc. 45:247. (Abstr.) 